\title{
OPEN
}

Received: 1 March 2019

Accepted: 22 August 2019

Published online: 04 September 2019

\section{Inter-arm Blood Pressure Difference is Associated with Recurrent Stroke in Non-cardioembolic Stroke}

Patients

\author{
Yoonkyung Chang ${ }^{1}$, Jinkwon Kim $\mathbb{1 D}^{2}$, Yong-Jae Kim ${ }^{3}$ \& Tae-Jin Song ${ }^{1}$
}

Recurrent stroke increases mortality and aggravates the disability of stroke patients. We hypothesized that increased inter-arm systolic blood pressure difference and inter-arm diastolic blood pressure difference would be related to recurrent stroke in non-cardioembolic stroke patients. A total of 1226 consecutive non-cardioembolic first-ever ischemic stroke patients, in whom bilateral brachial blood pressures were measured by an automated ankle-brachial index measuring device, were included in our study. Recurrent stroke was defined as newly developed neurologic symptoms with relevant lesions on brain CT and/or MRI after 7 days or hospital discharge. Inter-arm systolic and diastolic blood pressure differences $\geq 10 \mathrm{mmHg}$ were noted in $9.7 \%$ (120/1226) and $5.0 \%$ (62/1226) of patients, respectively. During a median 24 months of follow-up, 105 (8.5\%) patients experienced recurrent stroke. Patients who had inter-arm systolic blood pressure difference $\geq 10 \mathrm{mmHg}$ showed increased risk of recurrent stroke (hazard ratio: $1.77,95 \%$ confidence interval: 1.04-3.00, $p=0.033$ ). Moreover, inter-arm diastolic blood pressure difference $\geq 10 \mathrm{mmHg}$ was also independently associated with increased risk of recurrent stroke (hazard ratio: $2.92,95 \%$ confidence interval: $1.59-5.34, p=0.001$ ). In conclusion, interarm blood pressure difference $\geq 10 \mathrm{mmHg}$ may be associated with increased risk recurrent stroke in non-cardioembolic stroke patients.

Systolic and diastolic blood pressures are important risk factors for occurrence and recurrence of stroke ${ }^{1}$. The latest guideline for management of hypertension recommended to check blood pressure in both arms ${ }^{2}$, and different result is often found when checked bilaterally. These inter-arm blood pressure differences (IABDs) are reported in general population (4\%), diabetic patients $(7 \%)$ and stroke patients $(10 \%)^{3,4}$.

Stroke is one of the leading causes of disability, loss of productivity, and poor functional outcome including mortality ${ }^{5,6}$. Disability and poor functional outcome from stroke cause serious burden to patients themselves and their caregivers ${ }^{6}$. Additionally, recurrent stroke accounts for $10-25 \%$ of the total stroke ${ }^{7}$. Recurrent stroke increases mortality and exacerbates the disability of stroke patients ${ }^{8}$. Therefore, identifying and modifying factors associated with recurrent stroke are important tasks for treating stroke patients.

IABD can be easily measured at outpatient clinic and can be used as an important indicator or predictor in clinical fields. The major cause of IABD includes atherosclerosis and stenosis due to various diseases in the aorta, subclavian arteries and their branches ${ }^{9}$. In stroke patients, considering the relationship between extensive atherosclerosis and poor clinical outcome ${ }^{10}$, IABD may also have an association with recurrent stroke. However, few studies have reported these issues ${ }^{11}$. Our hypothesis is that increased IABD would be related with recurrent stroke in non-cardioembolic stroke patients.

\section{Results}

Demographics and comparisons of clinical variables according to IABD $\geq \mathbf{1 0} \mathbf{m m H g}$. There were no statistical difference of baseline demographics between patients included in the analysis and those excluded, except for age (Supplementary Table 1). Overall, 61.4\% (753/1226) were male, and the mean age was $65.0 \pm 11.8$

\footnotetext{
${ }^{1}$ Department of Neurology, Mokdong Hospital, Ewha Womans University College of Medicine, Seoul, Korea. ${ }^{2}$ Department of Neurology, Gangnam Severance Hospital, Yonsei University College of Medicine, Seoul, Korea. ${ }^{3}$ Department of Neurology, Eunpyeong St. Mary's Hospital, Catholic University of Korea, Seoul, Korea. Correspondence and requests for materials should be addressed to T.-J.S. (email: knstar@ewha.ac.kr)
} 
years. The ankle-brachial index (ABI) examination was performed at median 4 days [interquartile range 3-6 days]. In total, 148 (12.1\%) patients were prescribed antihypertensive medications before performing ABI. Among these 148 patients, 99 (66.9\%) had been prescribed intravenous labetalol only, while 23 (15.5\%) patients were prescribed intravenous perdipine and labetalol. Patients who received both oral and intravenous antihypertensive agents were $11(7.4 \%)$, and $15(10.1 \%)$ patients were prescribed oral antihypertensive agents only.

The systolic (IASBD) and diastolic (IADBD) blood pressure difference $\geq 10 \mathrm{mmHg}$ was noted in $9.7 \%$ $(120 / 1226)$ and $5.0 \%(62 / 1226)$, respectively. The patients with IASBD $\geq 10 \mathrm{mmHg}$ had more frequent history of hypertension, coronary artery disease (CAD), metabolic syndrome, regular alcohol intake, left ventricular hypertrophy, large artery atherosclerosis stroke subtype, cerebral atherosclerosis, and high-grade white matter hyperintensities. Moreover, body mass index, pulse rate, systolic blood pressure, diastolic blood pressure, and baPWV were higher in patients with IASBD $\geq 10 \mathrm{mmHg}$ compared to those with IASBD $<10 \mathrm{mmHg}$ (Table 1). Patients with $\mathrm{IADBD} \geq 10 \mathrm{mmHg}$ had more frequent history of $\mathrm{CAD}$, regular alcohol intake, left ventricular hypertrophy, cerebral atherosclerosis, and high-grade white matter hyperintensities. In addition, body mass index, National Institutes of Health Stroke Scale (NIHSS) score, pulse rate, systolic blood pressure, and diastolic blood pressure were higher in patients with IADBD $\geq 10 \mathrm{mmHg}$ compared to those with IADBD $<10 \mathrm{mmHg}$ (Table 1).

Association between IABD and recurrent stroke. During follow-up (median 24 months, interquartile range 14-32 months), 105 (8.6\%) patients had experienced recurrent stroke. The recurrent stroke was more frequently demonstrated in the IASBD $\geq 10 \mathrm{mmHg}$ group compared with the IASBD $<10 \mathrm{mmHg}$ group $(17.5 \%$ vs. $7.5 \%, \mathrm{p}<0.001)$ and in the IADBD $\geq 10 \mathrm{mmHg}$ group compared with the IADBD $<10 \mathrm{mmHg}$ group $(24.2 \%$ vs. $7.7 \%, \mathrm{p}<0.001)$, respectively. Considering recurrent stroke subtypes, large artery atherosclerosis $(71.4 \%$ vs. $28.6 \%$ ) and two or more causes identified (19\% vs. $17.9 \%$ ) were more frequently noted in the IASBD $\geq 10 \mathrm{mmHg}$ group compared with the IASBD $<10 \mathrm{mmHg}$ group $(\mathrm{p}=0.007)$. Furthermore, hemorrhagic stroke occurred less frequently in the IASBD $\geq 10 \mathrm{mmHg}$ group compared with the IASBD $<10 \mathrm{mmHg}$ group $(0.0 \%$ vs. $6.0 \%)$ (Table 2). For diastolic blood pressure differences, there was no statistical significance between patients with IADBD $\geq 10 \mathrm{mmHg}$ or IADBD $<10 \mathrm{mmHg}$ (Table 2), even though a similar tendency of recurrent stroke subtypes was noted for those with systolic blood pressure differences. Considering the location of recurrent stroke, patients with IASBD $\geq 10 \mathrm{mmHg}$ had a tendency of recurrent stroke in posterior circulation $(61.9 \% \mathrm{vs.} 40.5 \%, p=0.077)$. In contrast, there was no difference in the location of recurrent stroke in patients with IADBD $\geq 10 \mathrm{mmHg}$ compared to IADBD $<10 \mathrm{mmHg}$. (Recurrent stroke in posterior circulation: $53.3 \%$ vs. $43.3 \%, \mathrm{p}=0.471$ ).

Kaplan-Meier curves demonstrated that recurrent stroke depended on IASBD $\geq 10 \mathrm{mmHg}(\mathrm{p}=0.001)$ and $\mathrm{IADBD} \geq 10 \mathrm{mmHg}(\mathrm{p}=0.001)$ (Fig. 1). In multivariate analysis, IASBD $\geq 10 \mathrm{mmHg}$ was significantly related with recurrent stroke (HR: $1.77,95 \%$ CI: $1.04-3.00, \mathrm{p}=0.033$ ). Furthermore, IADBD $\geq 10 \mathrm{mmHg}$ was significantly associated with recurrent stroke (HR: 2.92, 95\% CI: 1.59-5.34, $\mathrm{p}=0.039$ ) (Table 3). Patients with both IASBD and IADBD $\geq 10 \mathrm{mmHg}$ were also associated with recurrent stroke (HR: 3.02, 95\% CI: 1.54-5.91, $\mathrm{p}=0.001$ ) (Table 3).

In subgroup analysis regarding the relationship of recurrent stroke with IABD, no subgroups showed significant difference except IASBD with increased baPWV $(>20.0 \mathrm{~m} / \mathrm{s})$ (Supplementary Table 2). The IASBD $\geq 10 \mathrm{mmHg}$ was associated with recurrent stroke in patients with increased baPWV $(>20.0 \mathrm{~m} / \mathrm{s})(\mathrm{HR}: 3.83,95 \%$ CI: $2.20-6.65)$, $(\mathrm{p}$ for interaction $=0.007)$.

\section{Discussion}

Our study showed that IASBD and/or IADBD $\geq 10 \mathrm{mmHg}$ was associated with recurrent stroke after adjustment for stroke severity (NIHSS), cerebral atherosclerosis, baPWV, and high-grade white matter hyperintensities, which were closely related factors for stroke. Thus, our study suggests that IASBD or IADBD, which can be easily measured in a clinical field, may be an independent factor for associating or predicting recurrent stroke in non-cardioembolic stroke patients.

Our study demonstrated that IASBD and/or IADBD $\geq 10 \mathrm{mmHg}$ was associated with recurrent stroke after non-cardioembolic stroke. Previous studies reported that IABD is related with vascular death and all-cause mortality $^{12}$, and these results were consistently noted in populations without known cardiovascular disease ${ }^{13}$ and in chronic kidney disease patients ${ }^{14}$. In elderly patients with hypertension, IASBD $\geq 10 \mathrm{mmHg}$ was an independent risk factor for increasing the risk of cardiovascular disease and mortality ${ }^{15}$. In contrast, the Framingham Heart Study reported no significant relationship with IABD and mortality ${ }^{16}$. However, up to now, preceding studies regarding IABD and recurrent stroke are rare. In a previous study of patients with acute ischemic stroke, IASBD and/or IADBD $\geq 10 \mathrm{mmHg}$ was associated with long-term mortality ${ }^{11}$. In patients with non-cardioembolic stroke, cerebral artery stenosis, which is a major predictor for poor prognosis after stroke, was diversely associated with $\mathrm{IABD}^{4}$. Another study showed low ABI was associated with recurrent stroke in patients with acute cerebral infarction ${ }^{17}$. Our study supports these findings and may give additive information for the associations of IABD and stroke recurrence. Moreover, bi-brachial blood pressure measurements might play a role as a screening tool for stroke patients to estimate the possibility of recurrent stroke in non-cardioembolic stroke patients.

Our study demonstrated that large artery atherosclerosis stroke subtype was more frequently noted in the IASBD $\geq 10 \mathrm{mmHg}$ group than in the IASBD $<10 \mathrm{mmHg}$ group for the stroke subtype of recurrent stroke. These results are consistent with previous findings that $\mathrm{IABD}$ is associated with cerebral atherosclerosis ${ }^{4}$, which is an important risk factor for ischemic stroke occurrence or recurrence. Another study also revealed association of arterial stiffness index and large artery atherosclerosis stroke subtype ${ }^{18}$, and the results of previous studies in which large artery atherosclerosis was associated with asymptomatic lacunar infarction ${ }^{19}$. Meanwhile, hemorrhagic stroke subtype was less frequently noted in the IASBD $\geq 10 \mathrm{mmHg}$ group than in those with IASBD $<10 \mathrm{mmHg}$. In contrast to our results, previous studies have revealed large artery atherosclerosis, such as aortic atheroma, was significantly associated with cerebral microbleeds that act as imaging biomarkers for future 


\begin{tabular}{|c|c|c|c|c|c|c|c|}
\hline & $\begin{array}{l}\text { Total } \\
(n=1226)\end{array}$ & \begin{tabular}{|l|} 
IASBD \\
$<10 \mathrm{mmHg}$ \\
$(\mathrm{n}=1109)$
\end{tabular} & \begin{tabular}{|l|} 
IASBD \\
$\geq 10 \mathrm{mmHg}$ \\
$(\mathrm{n}=117)$
\end{tabular} & $p$ value & $\begin{array}{l}\text { IADBD } \\
<10 \mathrm{mmHg} \\
(\mathrm{n}=1166)\end{array}$ & $\begin{array}{l}\text { IADBD } \\
\geq 10 \mathrm{mmHg} \\
(\mathrm{n}=60)\end{array}$ & $p$ value \\
\hline \multicolumn{8}{|l|}{ Demographics } \\
\hline Sex (male) & $753(61.4)$ & $683(61.6)$ & $70(59.8)$ & 0.710 & $720(61.7)$ & $33(55.0)$ & 0.295 \\
\hline Age, years & $65.0 \pm 11.8$ & $65.0 \pm 11.6$ & $65.2 \pm 13.6$ & 0.841 & $65.0 \pm 11.7$ & $65.4 \pm 13.3$ & 0.780 \\
\hline \multicolumn{8}{|l|}{ Risk factors } \\
\hline Hypertension & $901(73.5)$ & $807(72.8)$ & $94(80.3)$ & 0.078 & $854(73.2)$ & $47(78.3)$ & 0.384 \\
\hline Diabetes mellitus & $415(33.8)$ & $372(33.5)$ & $43(36.8)$ & 0.485 & $398(34.1)$ & $17(28.3)$ & 0.354 \\
\hline Hypercholesterolemia & $185(15.1)$ & $163(14.7)$ & $22(18.8)$ & 0.238 & $177(15.2)$ & $8(13.3)$ & 0.697 \\
\hline Smoking & $321(26.2)$ & $288(26.0)$ & $33(28.2)$ & 0.601 & $305(26.2)$ & $16(26.7)$ & 0.930 \\
\hline Coronary artery disease & $250(20.4)$ & $212(19.1)$ & $38(32.5)$ & 0.001 & $232(19.9)$ & $18(30.0)$ & 0.058 \\
\hline Metabolic syndrome & $502(40.9)$ & $440(39.7)$ & $62(53.0)$ & 0.005 & $480(41.2)$ & $22(36.7)$ & 0.489 \\
\hline Alcohol intake & $140(11.4)$ & $118(10.6)$ & $22(18.8)$ & 0.008 & $128(11.0)$ & $12(20.0)$ & 0.032 \\
\hline Left ventricular hypertrophy & $175(14.3)$ & $136(12.3)$ & $39(33.3)$ & 0.001 & $155(13.3)$ & $20(33.3)$ & 0.001 \\
\hline Body mass index, $\mathrm{kg} / \mathrm{m}^{2}$ & $24.1 \pm 3.0$ & $24.0 \pm 2.9$ & $25.6 \pm 3.8$ & 0.001 & $24.1 \pm 3.0$ & $25.5 \pm 3.6$ & 0.004 \\
\hline Familial history of stroke & $325(26.5)$ & $289(26.1)$ & $36(30.8)$ & 0.272 & $304(26.1)$ & $21(35.0)$ & 0.127 \\
\hline $\begin{array}{l}\text { Antihypertensive treatment } \\
\text { before ABI examination }\end{array}$ & $148(12.1)$ & $138(12.4)$ & $10(8.5)$ & 0.219 & $142(12.2)$ & $6(10.0)$ & 0.613 \\
\hline Thrombolytic therapy & $120(9.8)$ & $104(9.4)$ & $16(13.7)$ & 0.137 & $111(9.5)$ & $9(15.0)$ & 0.164 \\
\hline NIHSS & $4.0 \pm 4.7$ & $4.0 \pm 4.5$ & $4.1 \pm 4.2$ & 0.714 & $3.9 \pm 4.5$ & $5.1 \pm 4.5$ & 0.048 \\
\hline Stroke subtype & & & & 0.001 & & & 0.001 \\
\hline Large artery atherosclerosis & $359(29.3)$ & $308(27.8)$ & $51(43.6)$ & & $334(28.6)$ & $25(41.7)$ & \\
\hline Lacune & $357(29.1)$ & $346(31.2)$ & $11(9.4)$ & & $352(30.2)$ & $5(8.3)$ & \\
\hline Undetermined negative & $357(29.1)$ & $321(28.9)$ & $36(30.8)$ & & $339(29.1)$ & $18(30.0)$ & \\
\hline $\begin{array}{l}\text { Undetermined, two or more } \\
\text { causes identified }\end{array}$ & $153(12.5)$ & $134(12.1)$ & $19(16.2)$ & & $141(12.1)$ & $12(20.0)$ & \\
\hline Cerebral atherosclerosis & & & & 0.001 & & & 0.001 \\
\hline $\begin{array}{l}\text { Extracranial atherosclerosis } \\
\text { only }\end{array}$ & $179(14.6)$ & $162(14.6)$ & $17(14.5)$ & & $170(14.6)$ & $9(15.0)$ & \\
\hline $\begin{array}{l}\text { Intracranial atherosclerosis } \\
\text { only }\end{array}$ & $417(34.0)$ & $375(33.8)$ & 42 (35.9) & & $391(33.5)$ & $26(43.3)$ & \\
\hline $\begin{array}{l}\text { Both extra- and intracranial } \\
\text { atherosclerosis }\end{array}$ & $136(11.1)$ & $104(9.4)$ & $32(27.4)$ & & $118(10.1)$ & $18(30.0)$ & \\
\hline \multicolumn{8}{|c|}{ Previous medication before admission } \\
\hline Anti-thrombotics & $281(22.9)$ & $261(23.5)$ & $20(17.1)$ & 0.115 & $271(23.2)$ & $10(16.7)$ & 0.237 \\
\hline Lipid lowering agents & $221(18.0)$ & $202(18.2)$ & $19(16.2)$ & 0.597 & $212(18.2)$ & $9(15.0)$ & 0.532 \\
\hline \multicolumn{8}{|l|}{ Discharge medication } \\
\hline Anti-thrombotics & $1201(98.0)$ & $1086(97.9)$ & $115(98.3)$ & 0.791 & $1144(98.1)$ & $57(95.0)$ & 0.119 \\
\hline Lipid lowing agents & $1153(94.0)$ & $1039(93.7)$ & $114(97.4)$ & 0.103 & $1094(93.8)$ & $59(98.3)$ & 0.150 \\
\hline \multicolumn{8}{|l|}{ Ankle-brachial index parameters } \\
\hline Pulse rate, per/min & $69.3 \pm 12.2$ & $69.1 \pm 12.0$ & $72.0 \pm 3.8$ & 0.029 & $69.2 \pm 12.0$ & $72.5 \pm 14.8$ & 0.075 \\
\hline Mean arm SBP, mmHg & $149.6 \pm 22.5$ & $146.6 \pm 20.7$ & $159.3 \pm 23.3$ & 0.001 & $147.1 \pm 20.6$ & $160.8 \pm 29.7$ & 0.001 \\
\hline Mean arm DBP, mmHg & $85.7 \pm 12.6$ & $83.4 \pm 12.0$ & $90.2 \pm 15.3$ & 0.001 & $83.8 \pm 12.0$ & $90.3 \pm 18.8$ & 0.010 \\
\hline Mean baPWV, $\mathrm{m} / \mathrm{s}$ & $19.9 \pm 4.9$ & $19.5 \pm 4.8$ & $20.7 \pm 5.9$ & 0.044 & $19.6 \pm 4.9$ & $20.3 \pm 4.7$ & 0.240 \\
\hline Mean ABI value & \begin{tabular}{|l|}
$1.1 \pm 0.2$ \\
\end{tabular} & $1.1 \pm 0.3$ & $1.0 \pm 0.1$ & 0.654 & $1.1 \pm 0.3$ & $1.1 \pm 0.1$ & 0.562 \\
\hline $\begin{array}{l}\text { High-grade white matter } \\
\text { hyperintensities }\end{array}$ & $287(23.4)$ & $242(21.8)$ & $45(38.5)$ & 0.001 & $267(22.9)$ & $20(33.3)$ & 0.063 \\
\hline $\begin{array}{l}\text { Poor functional outcome } \\
(\mathrm{mRS}>2)\end{array}$ & $303(24.7)$ & $253(22.8)$ & $50(42.7)$ & 0.001 & $271(23.2)$ & $32(53.3)$ & 0.001 \\
\hline
\end{tabular}

Table 1. Clinical characteristics and comparison of study patients with IASBD and IADBD $\geq 10 \mathrm{mmHg}$. Data are shown as $\mathrm{n}(\%)$ or mean \pm standard deviation. IASBD: inter-arm systolic blood pressure difference, IADBD: inter-arm diastolic blood pressure difference, NIHSS: National Institutes of Health Stroke Scale, SBP: systolic blood pressure, DBP: diastolic blood pressure, baPWV: brachial-ankle pulse wave velocity, HWHs: high-grade white matter hyperintensities, CMBs: cerebral microbleeds, HPVSs: high-grade perivascular spaces, ALIs: asymptomatic lacunar infarctions.

cerebral haemorrhage ${ }^{19,20}$. These results suggest that a large IABD causes cerebral hypoperfusion in the brain, resulting in an ischemic prone state rather than a hemorrhagic prone state, but further research is needed.

Several hypotheses may explain the relationship of IABD with recurrent stroke. IABD is related with advanced atherosclerotic disease in the aorta and its large branches ${ }^{9}$, which may cause an insufficient cerebral blood 


\begin{tabular}{|c|c|c|c|c|c|c|c|}
\hline & $\begin{array}{l}\text { Total } \\
(\mathrm{n}=105)\end{array}$ & $\begin{array}{l}\text { IASBD } \\
<10 \mathrm{mmHg} \\
(\mathrm{n}=84)\end{array}$ & $\begin{array}{l}\text { IASBD } \\
\geq 10 \mathrm{mmHg} \\
(\mathrm{n}=21)\end{array}$ & $p$ value & $\begin{array}{l}\text { IADBD } \\
<10 \mathrm{mmHg} \\
(\mathrm{n}=90)\end{array}$ & $\begin{array}{l}\text { IADBD } \\
\geq 10 \mathrm{mmHg} \\
(\mathrm{n}=15)\end{array}$ & $p$ value \\
\hline Subtypes of recurrent stroke & & & & 0.007 & & & 0.060 \\
\hline Large artery atherosclerosis & $39(37.1)$ & $24(28.6)$ & $15(71.4)$ & & $30(33.3)$ & $9(60.0)$ & \\
\hline Cardioembolism & $6(5.7)$ & $6(7.1)$ & $0(0.0)$ & & $6(6.7)$ & $0(0.0)$ & \\
\hline Lacune & $14(13.3)$ & $13(15.5)$ & $1(4.8)$ & & $14(15.6)$ & $0(0.0)$ & \\
\hline Undetermined negative & $22(21.0)$ & $21(25.0)$ & $1(4.8)$ & & $21(23.3)$ & $1(6.7)$ & \\
\hline $\begin{array}{l}\text { Undetermined, two or more } \\
\text { causes identified }\end{array}$ & $19(18.1)$ & $15(17.9)$ & $4(19.0)$ & & $14(15.6)$ & $5(33.3)$ & \\
\hline Hemorrhagic stroke & $5(4.8)$ & $5(6.0)$ & $0(0.0)$ & & $5(5.6)$ & $0(0.0)$ & \\
\hline Location of stroke recurrence & & & & 0.077 & & & 0.471 \\
\hline Anterior circulation & $58(55.2)$ & $50(59.5)$ & $8(38.1)$ & & $51(56.7)$ & $7(46.7)$ & \\
\hline Posterior circulation & $47(44.8)$ & $34(40.5)$ & $13(61.9)$ & & $39(43.3)$ & $8(53.3)$ & \\
\hline
\end{tabular}

Table 2. Subtypes and location of stroke recurrence according to IASBD and IADBD $\geq 10 \mathrm{mmHg}$. Data are shown as $\mathrm{n}(\%)$ or mean \pm standard deviation. The $p$ values are derived by Chi's square test. IASBD: inter-arm systolic blood pressure difference, IADBD: inter-arm diastolic blood pressure difference.

(A)

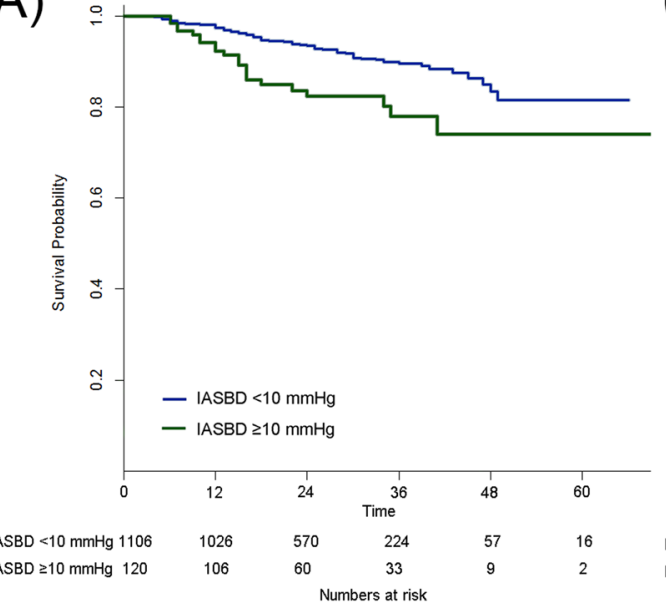

(B)

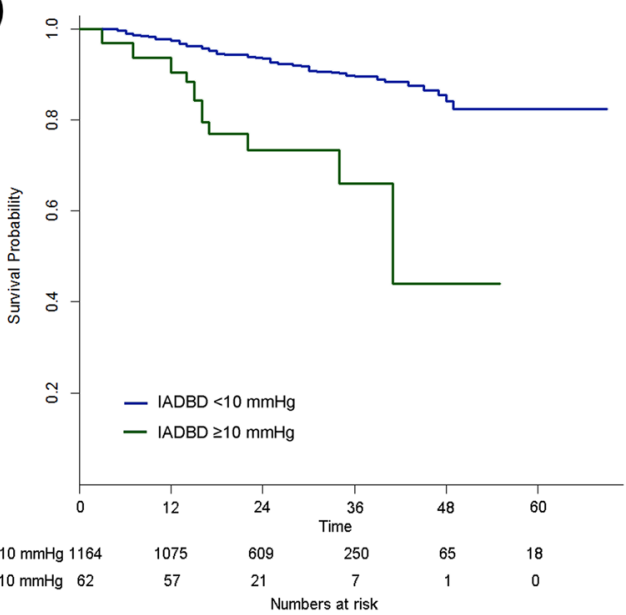

Figure 1. Kaplan-Meier survival plots of recurrent stroke regarding inter-arm systolic blood pressure difference $(\mathbf{A})$ and diastolic blood pressure difference $(\mathbf{B})$. The Kaplan-Meier curve shows that recurrent stroke depends on inter-arm systolic blood pressure difference $(\mathbf{A})(\mathrm{p}=0.001)$ and inter-arm diastolic blood pressure difference $(\mathbf{B})(\mathrm{p}=0.001)$.

flow $^{21}$. The hemodynamic dysfunction may be a part of the cause of recurrent stroke or poor clinical outcome ${ }^{22}$. Furthermore, larger atherosclerotic burden is correlated with early poor clinical outcome in stroke population ${ }^{10}$. In addition, previous study discovered that IABD resulting from one-arm ischemia in hypertensive or normotensive patients was related with flow-mediated dilatation ${ }^{23}$, which represents endothelial dysfunction. Increased arterial stiffness may be a link for our study. Arterial stiffness is associated with worse outcome in patients with acute cerebral infarction ${ }^{24-26}$. A population-based study showed large IABD was related with arterial stiffness, which is in line with our study ${ }^{27}$.

There are some limitations in our research. First, although consecutive patients were included in this study, the possibility of selection bias exists because of the retrospective study design. Second, it is difficult to generalize our findings to another population or cohort considering that our study population is limited to a single comprehensive center. Third, multiple, automatic, and simultaneous assessments are recommended for accurate IABD measurements rather than a single, manual, and sequential evaluation methods. We used an automatic and simultaneous measurement device; however, IABD was investigated only once during the ABI assessment and additional follow up data was lacking.

In conclusion, our results demonstrated that IASBD $\geq 10 \mathrm{mmHg}$ and/or IADBD $\geq 10 \mathrm{mmHg}$ is associated with recurrent stroke. An IABD $\geq 10 \mathrm{mmHg}$ could be a useful indicator of risk of recurrent stroke in non-cardioembolic stroke patients.

\section{Methods}

Study population. Patients admitted to our stroke center between January 2010 and August 2016, with firstever transient ischemic attack or acute ischemic stroke within 24 hours after symptom onset were enrolled ${ }^{28}$. For total 1782 patients, medical history, demographics, previous history of cardiovascular risk factors, neuroimaging findings and neurologic examination data were collected. All admitted stroke patients underwent chest x-ray, 


\begin{tabular}{|c|c|c|c|c|}
\hline & \multicolumn{2}{|c|}{ Frequency of recurrent stroke } & \multirow[b]{2}{*}{$\begin{array}{l}\text { Univariate HR }(95 \% \\
\text { CI) }\end{array}$} & \multirow[b]{2}{*}{$\begin{array}{l}\text { Multivariate }{ }^{\mathrm{a}} \mathrm{HR} \\
(95 \% \mathrm{CI})\end{array}$} \\
\hline & $\begin{array}{l}\text { Increased IABD } \\
\text { group }\end{array}$ & Reference group & & \\
\hline \multicolumn{5}{|l|}{ IASBD } \\
\hline$\geq 10 \mathrm{mmHg}$ vs. reference $(<10 \mathrm{mmHg})$ & $17.5 \%(21 / 120)$ & $7.5 \%(84 / 1106)$ & $2.26(1.40-3.65)^{*}$ & $1.77(1.04-3.00)^{*}$ \\
\hline$\geq 15 \mathrm{mmHg}$ vs. reference $(<15 \mathrm{mmHg})$ & $23.8 \%(15 / 63)$ & $7.7 \%(90 / 1163)$ & $3.20(1.85-5.54)^{*}$ & $1.92(1.03-3.58)^{*}$ \\
\hline $\begin{array}{l}\text { Absolute difference, } \mathrm{mmHg} \text { (continuous } \\
\text { variable) }\end{array}$ & $\mathrm{N} / \mathrm{A}$ & $\mathrm{N} / \mathrm{A}$ & $1.06(1.03-1.08)^{*}$ & $1.04(1.02-1.07)^{*}$ \\
\hline \multicolumn{5}{|l|}{ IADBD } \\
\hline$\geq 10 \mathrm{mmHg}$ vs. reference $(<10 \mathrm{mmHg})$ & $24.2 \%(15 / 62)$ & $7.7 \%(90 / 1164)$ & $4.06(2.35-7.04)^{*}$ & $2.92(1.59-5.34)^{*}$ \\
\hline$\geq 15 \mathrm{mmHg}$ vs. reference $(<15 \mathrm{mmHg})$ & $38.1 \%(8 / 21)$ & $8.0 \%(97 / 1205)$ & $6.09(2.95-12.57)^{*}$ & $3.61(1.63-7.99)^{*}$ \\
\hline $\begin{array}{l}\text { Absolute difference, } \mathrm{mmHg} \text { (continuous } \\
\text { variable) }\end{array}$ & $\mathrm{N} / \mathrm{A}$ & N/A & $1.12(1.08-1.17)^{*}$ & $1.10(1.05-1.15)^{*}$ \\
\hline $\begin{array}{l}\text { IASBD and IADBD } \geq 10 \mathrm{mmHg} \text { vs. } \\
\text { reference }(<10 \mathrm{mmHg})\end{array}$ & $28.2 \%(11 / 39)$ & $7.9 \%(94 / 1187)$ & $4.40(2.35-8.22)^{*}$ & $3.02(1.54-5.91)^{*}$ \\
\hline
\end{tabular}

Table 3. Frequency of developing clinical events and results of uni and multivariate analysis for recurrent stroke according to IABD. Cox proportional hazards regression were used for uni- and multivariate analysis. Data are shown as percent (number of case/numbers of total patients for each group) or hazard ratio (95\% confidence interval). ${ }^{*} p<0.05$. HR: hazard ratio, CI: confidence interval, IABD: inter-arm blood pressure difference, IASBD: inter-arm systolic blood pressure difference, IADBD: inter-arm diastolic blood pressure difference, N/A: not applicable. a: adjusted for sex, age, hypertension, diabetes mellitus, smoking, coronary artery disease, metabolic syndrome, National Institutes of Health Stroke Scale, stroke subtype, cerebral atherosclerosis, brachial-ankle pulse wave velocity, and high-grade white matter hyperintensities.

routine blood tests, and electrocardiography. Brain computed tomography (CT) and/or magnetic resonance imaging (MRI) and vascular imaging with MRI or CT were performed. In our department, ABI examination was investigated as one of the routine procedures to evaluate peripheral arterial occlusive lesions, performed at subacute stage (3-7 days after admission) ${ }^{29}$. Our study was approved by Ewha Womans University Mokdong hospital Institutional Review Board (IRB number 2017-04-017), and the requirement of obtaining patients' informed consent was waived because of the retrospective, cross-sectional, and observational nature of the study. All research was performed in accordance with relevant guidelines and regulations.

Among the 1782 patients, those with potential cardiac source of embolism (PCSE; $n=261$, which including persistent atrial fibrillation $(A F) /$ flutter $(n=190)$, paroxysmal AF $(n=45)$, sick sinus syndrome $(n=8)$, and other PCSE $(n=18)$ ), stroke subtype of other determined (rare causes) $(n=23)$, stroke subtype of undetermined incomplete evaluation $(\mathrm{n}=12)$ and transient ischemic attack $(\mathrm{n}=141)$ were not included. Patients with PCSE were not included because AF can cause inaccurate measurements of brachial-ankle pulse wave velocity (baPWV) and blood pressures (systolic and diastolic) ${ }^{4,30}$. Patients who did not perform brain MRI $(\mathrm{n}=22)$ or with poor image quality $(n=6)$ or with missing ABI data $(n=43)$ were excluded from this study. Patients having abnormal ABI (less than $0.9, \mathrm{n}=48$ ) were also excluded because baPWV results could be checked inaccurately ${ }^{31}$. The final number of subjects were 1,226 (Supplementary Fig. 1). Definitions for vascular risk factors are described in the supplemental methods and in a prior study ${ }^{4,32}$. Stroke was classified with the Trial of Org 10172 in Acute Stroke Treatment classification system ${ }^{33}$. Neurological severity was investigated using the NIHSS score. Antihypertensive treatment before ABI was defined as in case of treatment with intravenous or oral antihypertensive agents were performed before ABI examination was undertaken.

Measuring blood pressure in both arms and inter-arm blood pressure differences. Details for measurement of ABI were described in previous study ${ }^{34}$. In brief, The ABI test was performed by a well-trained examiner with more than 5 years of experience. Before taking the exam, patients had at least 5 minutes rest in a quiet room. The bilateral brachial systolic and diastolic blood pressures were measured automatically and simultaneously with an automated device for ABI test (VP-1000; Colin Co. Ltd, Komaki, Japan) in supine position after discharge of the bowels/bladder in the morning. Pressure cuffs were wrapped on both the brachial and posterior tibial arteries to measure the arterial blood pressure using the oscillometric method ${ }^{34}$. The ABI test was performed after the patients became neurologically stable. A large systolic (IASBD) or diastolic IABD (IADBD) was defined as an absolute inter-arm blood pressure difference $\geq 10 \mathrm{mmHg}$, which is frequently used and validated for major cardiovascular outcome as a cut-off value ${ }^{3,35}$.

Cerebral atherosclerosis and high-grade white matter hyperintensities. The degree of intracranial and extracranial cerebral atherosclerosis (ICAS and ECAS) stenosis was measured using brain CT angiography, MR angiography and/or digital subtraction angiography ${ }^{19}$. The existence of arterial stenosis was defined as more than $50 \%$ reduction in luminal diameters ${ }^{36,37}$. The Fazekas score of $\geq 2$ in the deep or periventricular white matter on T2-weighted image or fluid-attenuated inversion recovery were defined as high-grade white matter hyperintensities ${ }^{38}$.

Outcome measures. The follow up schedule for the patients was three months, one year, and every year after discharge. In each follow up, vital signs, newly developed vascular risk factors, and recurrence of stroke were 
assessed by a well-trained stroke nurse and/or stroke specialist. If a patient could not make routine follow up, clinical data was obtained by telephone interview. Recurrent stroke was defined as newly developed neurologic symptoms with relevant lesions on brain CT and/or MRI after 7 days after an index stroke or hospital discharge. We estimated time from admission to the first recurrent stroke ${ }^{28}$.

Statistical analysis. For statistical analysis, we used R package (version 3.0.2; R Foundation for Statistical Computing, Vienna, Austria) and SPSS package (version 23.0, Chicago, IL, USA) programs for Windows. To compare groups according to the presence of IABD $\geq 10 \mathrm{mmHg}$, independent t-test, Mann-Whitney $U$ test, Chi-square test, and Fisher's exact test were performed. To investigate the association of IABD with recurrent stroke, the Kaplan-Meier estimator, log-rank test and Cox proportional hazards regression analysis were used. In multivariate analyses, age, sex and variables with $p<0.1$ in univariate analysis were included. For sensitivity analysis, IASBD $\geq 15 \mathrm{mmHg}$, IADBD $\geq 15 \mathrm{mmHg}$, and any increased IABD (systolic or diastolic) were also investigated ${ }^{4}$. Subgroup analyses included sex, age, body mass index, cerebral atherosclerosis, stroke subtype (non-lacunar stroke vs. lacunar stroke subtype) and baPWV. The p value of less than 0.05 by two-tailed was considered as having statistical significance.

\section{Data Availability}

The data that support the findings of this study are openly available in figshare at https://doi.org/10.6084/m9. figshare.7542770.

\section{References}

1. Hong, K. S. Blood Pressure Management for Stroke Prevention and in Acute Stroke. J Stroke 19, 152-165, https://doi.org/10.5853/ jos.2017.00164 (2017).

2. Whelton, P. K. et al. 2017 ACC/AHA/AAPA/ABC/ACPM/AGS/APhA/ASH/ASPC/NMA/PCNA Guideline for the Prevention, Detection, Evaluation, and Management of High Blood Pressure in Adults: A Report of the American College of Cardiology/ American Heart Association Task Force on Clinical Practice Guidelines. Hypertension 71, e13-e115, https://doi.org/10.1161/ hyp.0000000000000065 (2018).

3. Clark, C. E., Taylor, R. S., Shore, A. C. \& Campbell, J. L. Prevalence of systolic inter-arm differences in blood pressure for different primary care populations: systematic review and meta-analysis. Br J Gen Pract 66, e838-e847, https://doi.org/10.3399/bjgp16X687553 (2016).

4. Song, T. J. et al. Is obstructive sleep apnea associated with the presence of intracranial cerebral atherosclerosis? Sleep Breath $\mathbf{2 1}$, 639-646, https://doi.org/10.1007/s11325-016-1450-9 (2017).

5. Roger, V. L. et al. Heart disease and stroke statistics-2011 update: a report from the American Heart Association. Circulation 123, e18-e209, https://doi.org/10.1161/CIR.0b013e3182009701 (2011).

6. Shubhakaran, K. P. \& Chin, J. H. The global burden of neurologic diseases. Neurology 84, 758, https://doi.org/10.1212/ wnl.0000000000001251 (2015).

7. Kolominsky-Rabas, P. L. et al. A prospective community-based study of stroke in Germany-the Erlangen Stroke Project (ESPro): incidence and case fatality at 1,3, and 12 months. Stroke 29, 2501-2506 (1998).

8. Wang, A. et al. Effect of recurrent stroke on poor functional outcome in transient ischemic attack or minor stroke. Int J Stroke 11, Np80, https://doi.org/10.1177/1747493016641954 (2016).

9. Clark, C. E. \& Aboyans, V. Interarm blood pressure difference: more than an epiphenomenon. Nephrol Dial Transplant 30, 695-697, https://doi.org/10.1093/ndt/gfv075 (2015).

10. Roquer, J. et al. Atherosclerotic burden and early mortality in acute ischemic stroke. Arch Neurol 64, 699-704, https://doi. org/10.1001/archneur.64.5.699 (2007).

11. Kim, J. et al. Interarm blood pressure difference and mortality in patients with acute ischemic stroke. Neurology 80, 1457-1464, https://doi.org/10.1212/WNL.0b013e31828cf87c (2013).

12. Clark, C. E., Taylor, R. S., Shore, A. C., Ukoumunne, O. C. \& Campbell, J. L. Association of a difference in systolic blood pressure between arms with vascular disease and mortality: a systematic review and meta-analysis. Lancet 379, 905-914, https://doi. org/10.1016/s0140-6736(11)61710-8 (2012).

13. Aboyans, V. et al. The vital prognosis of subclavian stenosis. J Am Coll Cardiol 49, 1540-1545, https://doi.org/10.1016/j. jacc.2006.09.055 (2007).

14. Agarwal, R., Bunaye, Z. \& Bekele, D. M. Prognostic significance of between-arm blood pressure differences. Hypertension 51, 657-662, https://doi.org/10.1161/hypertensionaha.107.104943 (2008).

15. Clark, C. E., Taylor, R. S., Shore, A. C. \& Campbell, J. L. The difference in blood pressure readings between arms and survival: primary care cohort study. Bmj 344, e1327, https://doi.org/10.1136/bmj.e1327 (2012).

16. Weinberg, I., Gona, P., O'Donnell, C. J., Jaff, M. R. \& Murabito, J. M. The systolic blood pressure difference between arms and cardiovascular disease in the Framingham Heart Study. Am J Med 127, 209-215, https://doi.org/10.1016/j.amjmed.2013.10.027 (2014).

17. Tsivgoulis, G. et al. Low ankle-brachial index predicts early risk of recurrent stroke in patients with acute cerebral ischemia. Atherosclerosis 220, 407-412, https://doi.org/10.1016/j.atherosclerosis.2011.11.009 (2012).

18. Tuttolomondo, A. et al. Endothelial function and arterial stiffness indexes in subjects with acute ischemic stroke: Relationship with TOAST subtype. Atherosclerosis 256, 94-99, https://doi.org/10.1016/j.atherosclerosis.2016.10.044 (2017).

19. Song, T. J. et al. Association between Aortic Atheroma and Cerebral Small Vessel Disease in Patients with Ischemic Stroke. J Stroke 18, 312-320, https://doi.org/10.5853/jos.2016.00171 (2016).

20. Song, T. J. et al. Association of cerebral microbleeds with mortality in stroke patients having atrial fibrillation. Neurology 83 , 1308-1315, https://doi.org/10.1212/wnl.0000000000000862 (2014).

21. Ochoa, V. M. \& Yeghiazarians, Y. Subclavian artery stenosis: a review for the vascular medicine practitioner. Vasc Med 16, 29-34, https://doi.org/10.1177/1358863x10384174 (2011).

22. Caplan, L. R., Wong, K. S., Gao, S. \& Hennerici, M. G. Is hypoperfusion an important cause of strokes? If so, how? Cerebrovasc Dis 21, 145-153, https://doi.org/10.1159/000090791 (2006).

23. $\mathrm{Hu}, \mathrm{W}$. et al. The inter-arm diastolic blood pressure difference induced by one arm ischemia: a new approach to assess vascular endothelia function. PLoS One 9, e84765, https://doi.org/10.1371/journal.pone.0084765 (2014).

24. Tabata, N. et al. Relationship between asymptomatic intra-cranial lesions and brachial-ankle pulse wave velocity in coronary artery disease patients without stroke. Hypertens Res 40, 392-398, https://doi.org/10.1038/hr.2016.159 (2017).

25. Kim, J. et al. Brachial-ankle pulse wave velocity for predicting functional outcome in acute stroke. Stroke 45, 2305-2310, https://doi. org/10.1161/strokeaha.114.005576 (2014). 
26. Kim, J. et al. Brachial-ankle pulse wave velocity is a strong predictor for mortality in patients with acute stroke. Hypertension 64, 240-246, https://doi.org/10.1161/hypertensionaha.114.03304 (2014).

27. Canepa, M. et al. Relationship between inter-arm difference in systolic blood pressure and arterial stiffness in community-dwelling older adults. J Clin Hypertens (Greenwich) 15, 880-887, https://doi.org/10.1111/jch.12178 (2013).

28. Song, T. J. et al. Low Plasma Proportion of Omega 3-Polyunsaturated Fatty Acids Predicts Poor Outcome in Acute Non-Cardiogenic Ischemic Stroke Patients. J Stroke 17, 168-176, https://doi.org/10.5853/jos.2015.17.2.168 (2015).

29. Chung, J. W. et al. Blood pressure variability and the development of early neurological deterioration following acute ischemic stroke. J Hypertens 33, 2099-2106, https://doi.org/10.1097/hjh.0000000000000675 (2015).

30. Stergiou, G. S., Kollias, A., Destounis, A. \& Tzamouranis, D. Automated blood pressure measurement in atrial fibrillation: a systematic review and meta-analysis. J Hypertens 30, 2074-2082, https://doi.org/10.1097/HJH.0b013e32835850d7 (2012).

31. Motobe, K. et al. Cut-off value of the ankle-brachial pressure index at which the accuracy of brachial-ankle pulse wave velocity measurement is diminished. Circ J 69, 55-60 (2005).

32. Song, T. J., Chang, Y., Shin, M. J., Heo, J. H. \& Kim, Y. J. Low levels of plasma omega 3-polyunsaturated fatty acids are associated with cerebral small vessel diseases in acute ischemic stroke patients. Nutr Res 35, 368-374, https://doi.org/10.1016/j.nutres.2015.04.008 (2015).

33. Adams, H. P. Jr. et al. Classification of subtype of acute ischemic stroke. Definitions for use in a multicenter clinical trial. TOAST. Trial of Org 10172 in Acute Stroke Treatment. Stroke 24, 35-41 (1993).

34. Yamashina, A. et al. Validity, reproducibility, and clinical significance of noninvasive brachial-ankle pulse wave velocity measurement. Hypertens Res 25, 359-364 (2002).

35. Verberk, W. J., Kessels, A. G. \& Thien, T. Blood pressure measurement method and inter-arm differences: a meta-analysis. Am J Hypertens 24, 1201-1208, https://doi.org/10.1038/ajh.2011.125 (2011).

36. Samuels, O. B., Joseph, G. J., Lynn, M. J., Smith, H. A. \& Chimowitz, M. I. A standardized method for measuring intracranial arterial stenosis. AJNR Am J Neuroradiol 21, 643-646 (2000).

37. Barnett, H. J. M. et al. Beneficial effect of carotid endarterectomy in symptomatic patients with high-grade carotid stenosis. $N$ Engl J Med 325, 445-453, https://doi.org/10.1056/nejm199108153250701 (1991).

38. Fazekas, F., Chawluk, J. B., Alavi, A., Hurtig, H. I. \& Zimmerman, R. A. MR signal abnormalities at 1.5 T in Alzheimer's dementia and normal aging. AJR Am J Roentgenol 149, 351-356, https://doi.org/10.2214/ajr.149.2.351 (1987).

\section{Acknowledgements}

The study was supported by grants from the Basic Science Research Program through the National Research Foundation of Korea funded by the Ministry of Education (2018R1D1A1B07040959).

\section{Author Contributions}

Yoonkyung Chang and Tae-Jin song contributed to data collection and wrote the first draft of the manuscript. Jinkwon Kim performed data analysis. Yong-Jae Kim contributed to the design and implementation of the research. Tae-Jin song supervised the project. All authors discussed the results and commented on the manuscript.

\section{Additional Information}

Supplementary information accompanies this paper at https://doi.org/10.1038/s41598-019-49294-8.

Competing Interests: The authors declare no competing interests.

Publisher's note: Springer Nature remains neutral with regard to jurisdictional claims in published maps and institutional affiliations.

Open Access This article is licensed under a Creative Commons Attribution 4.0 International License, which permits use, sharing, adaptation, distribution and reproduction in any medium or format, as long as you give appropriate credit to the original author(s) and the source, provide a link to the Creative Commons license, and indicate if changes were made. The images or other third party material in this article are included in the article's Creative Commons license, unless indicated otherwise in a credit line to the material. If material is not included in the article's Creative Commons license and your intended use is not permitted by statutory regulation or exceeds the permitted use, you will need to obtain permission directly from the copyright holder. To view a copy of this license, visit http://creativecommons.org/licenses/by/4.0/.

(c) The Author(s) 2019 